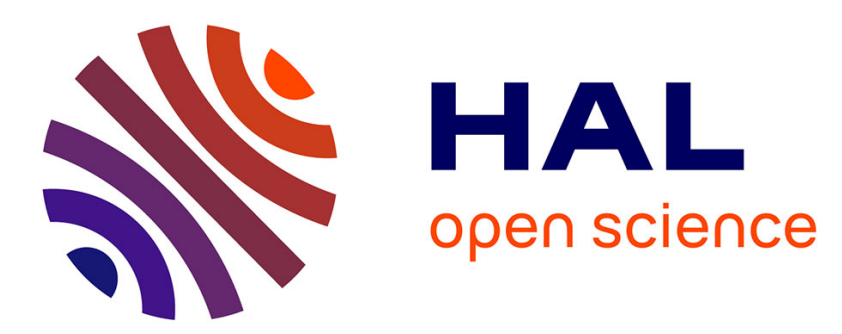

\title{
A first attempt to enhance the 2-D single crystal growth of a protein at an air/water interface from hydrodynamics
}

\author{
Laurent Drazek, J.F. Legrand, Laurent Davoust
}

\section{- To cite this version:}

Laurent Drazek, J.F. Legrand, Laurent Davoust. A first attempt to enhance the 2-D single crystal growth of a protein at an air/water interface from hydrodynamics. Journal of Crystal Growth, 2005, 275, pp.1467-1472. 10.1016/j.jcrysgro.2004.11.232 . hal-00203812

\section{HAL Id: hal-00203812 \\ https://hal.science/hal-00203812}

Submitted on 17 Feb 2020

HAL is a multi-disciplinary open access archive for the deposit and dissemination of scientific research documents, whether they are published or not. The documents may come from teaching and research institutions in France or abroad, or from public or private research centers.
L'archive ouverte pluridisciplinaire HAL, est destinée au dépôt et à la diffusion de documents scientifiques de niveau recherche, publiés ou non, émanant des établissements d'enseignement et de recherche français ou étrangers, des laboratoires publics ou privés. 


\title{
A first attempt to enhance the 2-D single-crystal growth of a protein at an air/water interface from hydrodynamics
}

\author{
L. Drazek ${ }^{\mathrm{a}}$, J.-F. Legrand ${ }^{\mathrm{b}}$, L. Davoust ${ }^{\mathrm{a}, *}$ \\ ${ }^{\mathrm{a}}$ UMR Laboratoire des Ecoulements Géophysiques et Industriels (LEGI), BP 53, 38041 Grenoble Cedex 9, France \\ ${ }^{\mathrm{b}}$ UMR SPrAM, CEA Grenoble/DRFMC, 17, rue des Martyrs, 38054 Grenoble Cedex 9, France
}

An alternative technique to grow a 2-D crystal of protein at a functionalized air/water interface is proposed. The first part of this paper briefly reviews 2 - D crystal growth at a fluid interface and deals with our first experiments on streptavidin whose 2-D (poly)crystallization ability is well known. In the experiments, the involved air/water interface is functionalized with a mixed lipidic monolayer made of DOPC and biotinylated lipids. The second part of the paper relates to an alternative strategy we propose in order to enhance the 2-D single-crystal growth of a protein at a liquid interface. The idea is to get benefit from an axisymmetric swirling flow driven in a water sub-phase confined within an annular channel. The swirl is expected to control the distribution of the proteins at the air/water interface and to promote the growth of a 2- D single crystal from the smallest to the largest radii (radial segregation). An analytical modelling based on a low Reynolds number asymptotic development demonstrates how two control parameters, the mean channel curvature and the Reynolds number of the shear flow, can be helpful in tuning the magnitude of the swirl and therefore the crystal growth.

Keywords: A1. Biocrystallization; A1. Fluid flows; A1. Interfaces; A2. Single-crystal growth; B1. Biological macromolecules; B1. Proteins

\section{Introduction}

In order to determine the molecular structure of a protein, techniques such as electron microscopy

\footnotetext{
*Corresponding author. Tel.: + 33476825038 ; fax: +33476825271 .

E-mail address: laurent.davoust@hmg.inpg.fr (L. Davoust).
}

or X-ray scattering are typically involved. These techniques require 2-D or 3-D protein crystals. Yet many proteins of great importance for molecular biologists, e.g. membrane proteins, do not crystallize in 3-D. A typical alternative is to promote the growth of a 2-D crystal at a functionalized air/ water interface. The general method devoted to produce 2-D crystals in small static wells has been 
exposed 20 years ago by Kornberg et al. [1,2]. The technique is based on a lipidic monolayer spread at the interface and is able to support the crystallization process. The proteins, initially solubilized in the bulk, are binding to the lipids by means of a high protein-affinity ligand $[1,3]$ or by use of metal-chelating lipid in connection with surface histidines [4-6].

Although chelating lipids have been involved in numerous studies for the last 10 years, specific binding of proteins is currently the most common technique. This crystallization process has been assumed to be a simple three-step mechanism for a very long time [1,7,8]: (i) molecular recognition between protein and ligand; (ii) 2-D diffusion of the protein-ligand complexes within the plane of the interface; and (iii) self-assembly leading to 2-D crystallization. The latter point indicates that 2-D crystals will preferentially grow in high protein density areas for which the locations within the interface mainly depend on the diffusion of the proteins initially solubilized in the sub-phase. As a consequence, diffusion-based techniques will provide polycrystals at the air/water interface limiting, thus, the resolution during structural determination. The aim of this work is to use hydrodynamics to control the spatial distribution of the proteins at the air/water interface and then to promote the growth of a 2-D single crystal expected to provide a better resolution during the determination of the protein structure.

\section{Experimental set-up and hydrodynamics modelling}

\subsection{State of art}

Most common 2-D crystallization experiments are currently made in cylindrical Teflon troughs filled with buffer solution. The lipidic monolayer is spread on the interface and a solution of proteins is injected within the sub-phase after equilibrium is reached. Among the numerous proteins studied for such crystallization processes, streptavidin is certainly the most popular [9-15]. Its structure was determined many years ago [16-18] and this has made possible the understanding of fundamentals

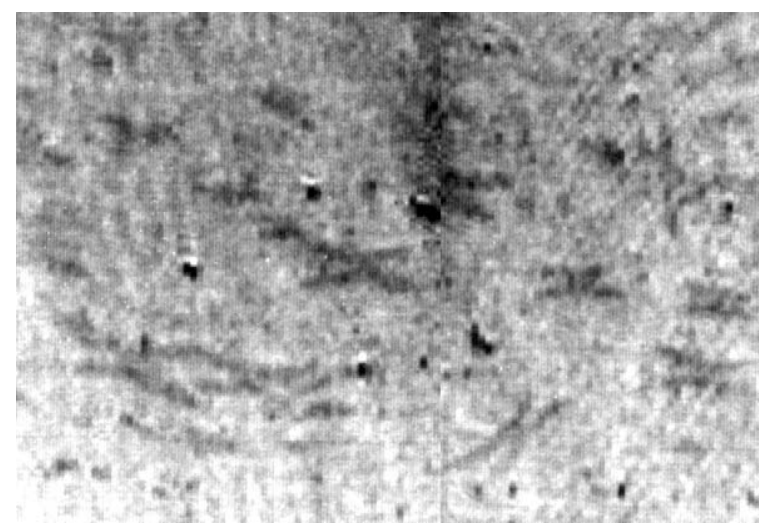

Fig. 1. X-shaped streptavidin crystals produced in a static well observed with BAM (scaling $1.4 \mathrm{~mm} \times 2.4 \mathrm{~mm}$ ).

of 2-D crystallization processes [19]. Its ability to form X- or H-shaped 2-D crystals easily (Fig. 1) makes it appropriate for developing, testing and qualifying new instruments.

\subsection{2-D streptavidin crystals}

Streptavidin was purchased from Sigma and diluted in a $(150 \mathrm{mM} \mathrm{NaCl} ; 10 \mathrm{mM}$ Tris- $\mathrm{HCl} ; \mathrm{pH}$ 7.5) buffer solution. The lipid monolayer consists in a $0.5 \mathrm{mg} / \mathrm{mL}$ mixture of (B-LC-DPPE:DOPC) (1:4)M/M. Experiments were conducted in a $5 \mathrm{~mL}$ Teflon trough with a $20 \mathrm{mg} / \mathrm{mL}$ solution of streptavidin. About $10 \mathrm{~min}$ after streptavidin injection, X-shaped 2-D crystals, $250 \mu \mathrm{m}$ long approximately, are observed within the interface (Fig. 1) with a commercial brewster angle microscope (miniBAM, NanoFilm Technologies, Gmbh).

\subsection{Experimental device}

The experimental trough of interest here stands as a Teflon annular channel with a free air/water interface, the side walls of the channel being maintained stationary (Fig. 2). Twelve magnets are mounted into a sealed annular Teflon ring lying on the floor. This ring rotates slowly by means of a magnetic coupling with magnets fixed on an independent annular brass plate mounted on 
a motoreducer axis. Rotation speed $(0.1-1 \mathrm{rpm})$ is controlled with a Hall-effect sensor set at the channel's periphery. The use of a closed-bottom channel geometry associated to a remote-control electromagnetic tool is original (if compared to previous similar set-ups [20-22]) and prevents us from loss of biological materials.

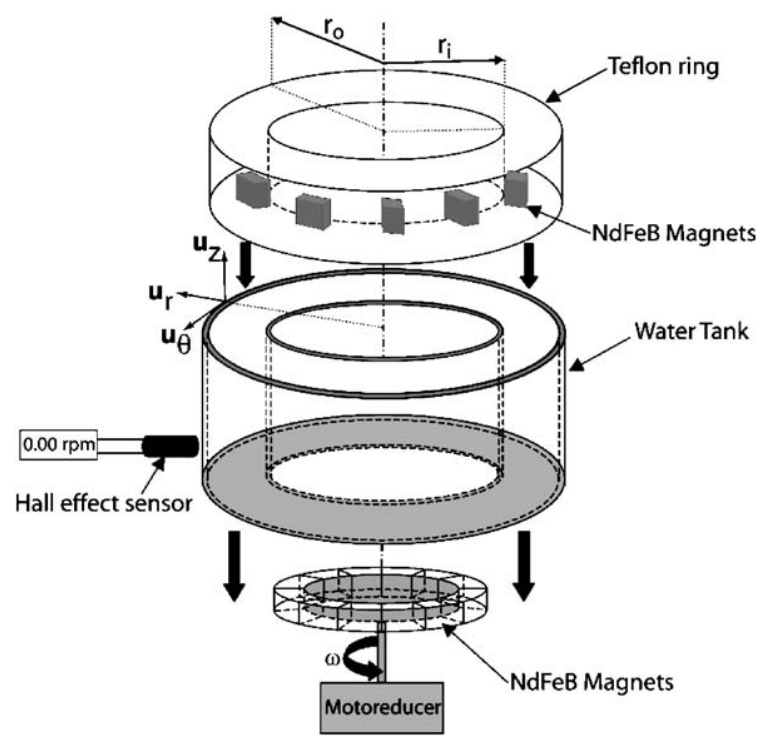

Fig. 2. Description of the three-parts rotating well $\left(r_{\mathrm{i}}=40 \mathrm{~mm}\right.$, $\left.r_{\mathrm{o}}=50 \mathrm{~mm}, h=10 \mathrm{~mm}\right)$. The Teflon ring is rotating by means of a magnetic coupling.
Slow motion of the floor yields a main azimuthal shear flow. The subsequent centrifugal inertia gives rise to a secondary recirculating flow within a meridian cross-section of the annular channel (Fig. 3). The basic idea is to get benefit from this recirculation not only to decrease the time for proteins to transport to the interface but also to radially segregate the proteins and consequently induce high-protein density areas which are expected to promote the growth of single 2-D crystals. In order to predict and understand the influence of the flow on the interfacial dynamics and to further thoroughly identify control parameters which could be representative of the quality of the crystals so-obtained, we propose an analytical modelling of the swirling axisymmetric flow within the sub-phase.

\subsection{Mathematical formulation}

Fig. 2 shows the geometry of the annulus and the coordinate system, with $r$ taken along the radial direction and $z$ along the vertical direction. The inner and outer radii of the trough are indicated by $r_{\mathrm{i}}$ and $r_{\mathrm{o}}$, respectively, and the depth is denoted by $h$. All quantities are made nondimensional taking the outer radius $r_{\mathrm{o}}$ as the length scale and $1 / \Omega$ as the time scale, where $\Omega$ is the angular speed rate of the floor. We also

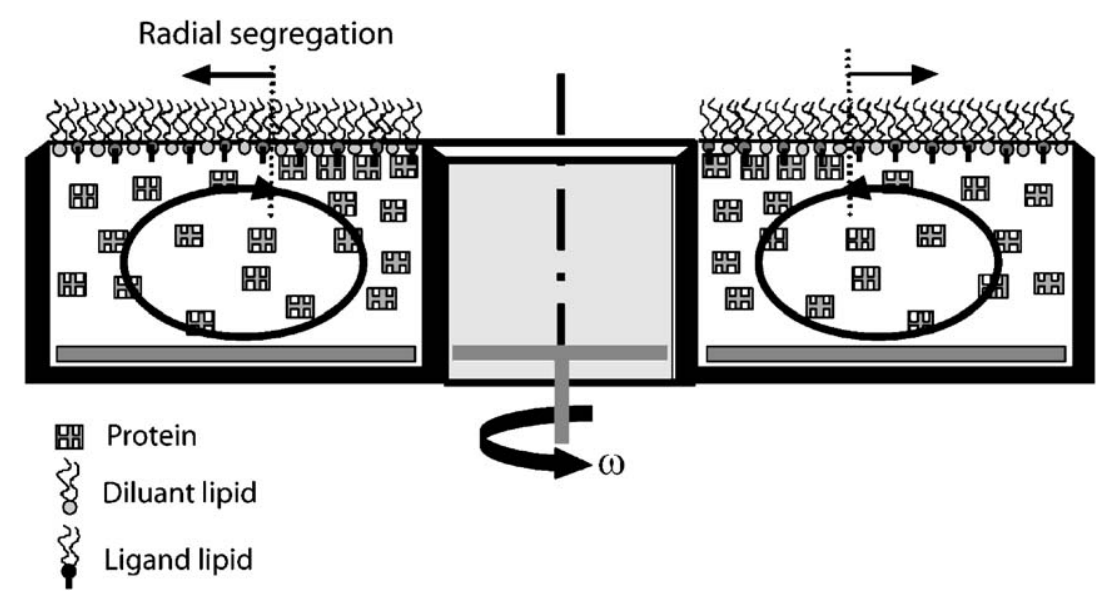

Fig. 3. Cross-section of the channel and description of the crystallization process as expected. The recirculating flow drives the proteins to the interface. For those already adsorbed, the flow is expected to be responsible for a radial segregation from the outer to the inner radii. 
introduce the non-dimensional Reynolds number defined by $\operatorname{Re}=\left(r_{\mathrm{o}}^{2} \Omega\right) / v$ and a geometric aspect ratio defined by $\delta=\mathrm{e} / r_{\mathrm{o}}$, where $e=r_{\mathrm{o}}-r_{\mathrm{i}}$ stands as the width of the annulus. The 3-D flow field into the domain $D=\left[r_{\mathrm{i}} / r_{\mathrm{o}}, 1\right] \times\left[0, h / r_{\mathrm{o}}\right]$ will be described by the azimuthal flow $v_{\theta} \mathbf{u}_{\theta}$ and the 2-D meridian flow $\mathbf{v}_{\perp}=v_{r}(r, z) \mathbf{u}_{r}+v_{z}(r, z) \mathbf{u}_{z}$ with components $\left(v_{r}, v_{z}\right)$ derived from the stream function $\psi$ and the vorticity $\omega$ :

$$
v_{r}=-\frac{\partial \psi}{\partial z}, v_{z}=\frac{1}{r} \frac{\partial(r \psi)}{\partial r} \quad \text { and }
$$$$
\omega=\mathbf{u}_{\theta} \cdot\left(\nabla \times \mathbf{v}_{\perp}\right) \text {. }
$$

The Navier-Stokes equations can be written as a set of equations coupled to each other from their non-linear forcing terms

$$
\begin{aligned}
E^{2}\left(v_{\theta}\right)= & \operatorname{Re}\left\{\nabla \times\left(v_{\theta} \mathbf{u}_{\theta}\right)\right. \\
& \left.\times\left[\nabla \times \psi \mathbf{u}_{\theta}\right]\right\} \cdot \mathbf{u}_{\theta}, \\
E^{2}(\omega)= & \operatorname{Re} \mathbf{u}_{\theta} \cdot \nabla \times\left\{\left(\nabla \times \mathbf{v}_{\theta}\right)\right. \\
& \left.\times \mathbf{v}_{\theta}+\omega \mathbf{u}_{\theta} \times\left[\nabla \times \psi \mathbf{u}_{\theta}\right]\right\},
\end{aligned}
$$

$E^{2}(\psi)=-\omega$,

the differential operator $E^{2}()$ being defined by $E^{2}=\left(\partial^{2} / \partial z^{2}\right)+\left(\partial^{2} / \partial r^{2}\right)+(1 / r) \partial / \partial r-1 / r^{2}$.

The associated no-slip and no-penetration boundary conditions at the floor and at the walls can be written as

$$
\begin{gathered}
v_{\theta}=0, \psi=0, \frac{\partial \psi}{\partial r}=0 \\
\text { at } r=\frac{r_{\mathrm{i}}}{r_{\mathrm{o}}} \text { and } 0<z \leqslant \frac{h}{r_{\mathrm{o}}}, \\
v_{\theta}=0, \psi=0, \frac{\partial \psi}{\partial r}=0 \\
\text { at } r=1 \text { and } 0<z \leqslant \frac{h}{r_{\mathrm{o}}}, \\
v_{\theta}=r, \psi=0, \frac{\partial \psi}{\partial z}=0 \\
\text { at } \frac{r_{\mathrm{i}}}{r_{\mathrm{o}}}<r<1 \text { and } z=0 .
\end{gathered}
$$

The impermeability of the free air/water interface and the interfacial tangential momentum balance lead to

$$
\begin{aligned}
& \begin{array}{l}
\psi=0 \\
\omega=0,
\end{array} \\
& \frac{\partial v_{\theta}}{\partial z}=\delta B o \frac{\partial}{\partial r}\left[\frac{1}{r} \frac{\partial\left(r v_{\theta}\right)}{\partial r}\right] \\
& \text { at } \frac{r_{\mathrm{i}}}{r_{\mathrm{o}}}<r<1 \text { and } z=\frac{h}{r_{\mathrm{o}}},
\end{aligned}
$$

with the Boussinesq number $B o=\varepsilon / \mu \mathrm{e}$, the interfacial shear viscosity $\varepsilon$, the bulk shear viscosity $\mu$. The $B o$ number is the non-dimensional number which gives information about the interfacial rheology.

To simplify calculations, the mathematical model is solved in the case of a free (noncontaminated) interface $(B o=0)$. The RHS of the last boundary condition Eq. (7) consequently vanishes leading to the typical free-surface boundary condition

$\frac{\partial v_{\theta}}{\partial z}=0 \quad$ at $\frac{r_{\mathrm{i}}}{r_{\mathrm{o}}}<r<1$ and $z=\frac{h}{r_{\mathrm{o}}}$.

In order to solve this mathematical problem, two main difficulties have to be overcome: (i) the forcing terms of Eqs. (1)-(2) are non-linear; and (ii) $\psi$-boundary conditions are overspecified at the expense of $\omega$-boundary conditions. Taking advantage of the slow rotation speed of the floor $(R e<1)$, Eqs. (1) and (2) can be linearized making use of a regular perturbation series with $R e$ as small parameter, leading to a set of linear problems [23] which can be solved separately. The general solution of the flow is written as

$v_{\theta}=v_{\theta, 0}+\operatorname{Re} v_{\theta, 1}+\operatorname{Re}^{2} v_{\theta, 2}+\cdots$

$\psi=\psi_{0}+\operatorname{Re} \psi_{1}+\operatorname{Re}^{2} \psi_{2}+\cdots$

$\omega=\omega_{0}+\operatorname{Re} \omega_{1}+\operatorname{Re}^{2} \omega_{2}+\cdots$

Solution to the second difficulty mentioned above is inspired from Quartapelle [24] making use of an integral vorticity boundary condition derived from 
the second Green identity generalized to $E^{2}$

$$
\begin{aligned}
& \int_{D} r \Phi(r, z) \omega(r, z) \mathrm{d} A \\
& =-\int_{r_{\mathrm{i}} / r_{\mathrm{o}}}^{1} r \Phi\left(r, \frac{h}{r_{\mathrm{o}}}\right) \frac{\partial \psi}{\partial z}\left(r, \frac{h}{r_{\mathrm{o}}}\right) \mathrm{d} r,
\end{aligned}
$$

where $\Phi$ is, an arbitrary scalar field defined in such a way that $E^{2}(\Phi)=0$. By using this new integral condition, the three overnumerous $\psi$ boundary conditions can be reformulated as boundary conditions for the vorticity function $\omega$.

At each order in $R e$, the three different unknowns $v_{\theta}, \omega$ and $\psi$ will be developed as double series on three different bases of orthogonal eigenfunctions depending on the nature of the interfacial boundary conditions (Dirichlet or Neumann).

\section{Discussion}

To our knowledge, our analytical treatment is original in that inertia which gives rise to the

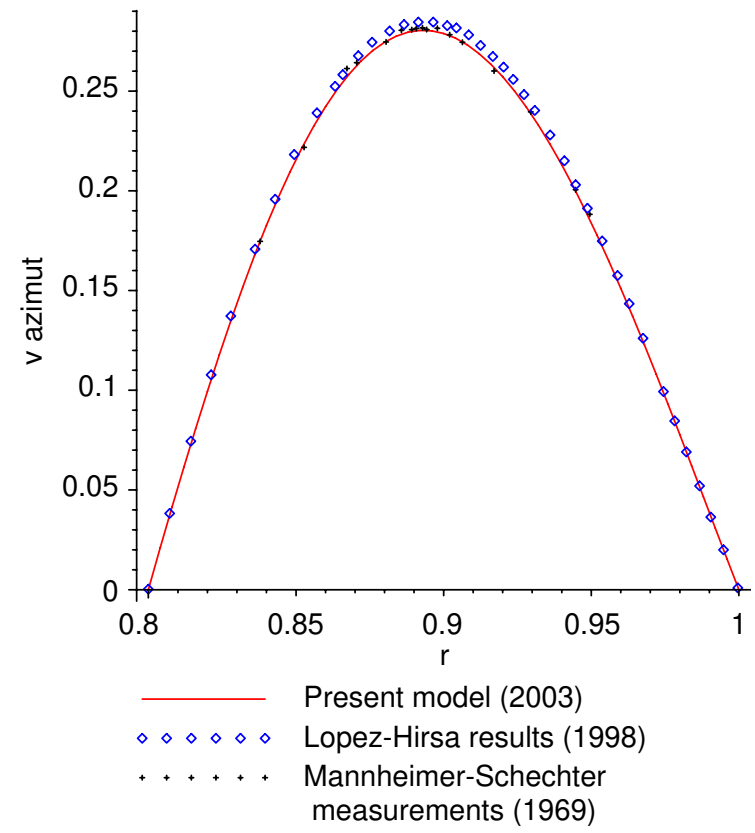

Fig. 4. Comparison of the analytical non-dimensional azimuthal flow field $v_{\theta} \mathbf{u}_{\theta}$ at the interface $\left(z=h / r_{\mathrm{o}}\right)$, calculated up to $O\left(R e^{3}\right)$ with numerical computations [22] and experiments [21] $\left(R e=r_{\mathrm{o}}^{2} \Omega / v=73\right.$ for $r_{\mathrm{i}} / r_{\mathrm{o}}=0.8$ and $\left.h / r_{\mathrm{o}}=0.2\right)$. meridian recirculation is fully taken into account to solve the Navier-Stoke equations and is not neglected as in the usual case of the Stoke's equation $[20,25]$.

In order to allow comparison with formerly published numerical results [22] and experimental studies [21], $r_{\mathrm{i}}, r_{\mathrm{O}}$ and $h$ are set to values such as $r_{\mathrm{i}} / r_{\mathrm{o}}=0.8$ and $h / r_{\mathrm{o}}=0.2$. As shown in Fig. 4 , our results for the azimuthal flow $v_{\theta} \mathbf{u}_{\theta}$ at the interface limited to $O\left(R e^{3}\right)$ are quite consistent with the
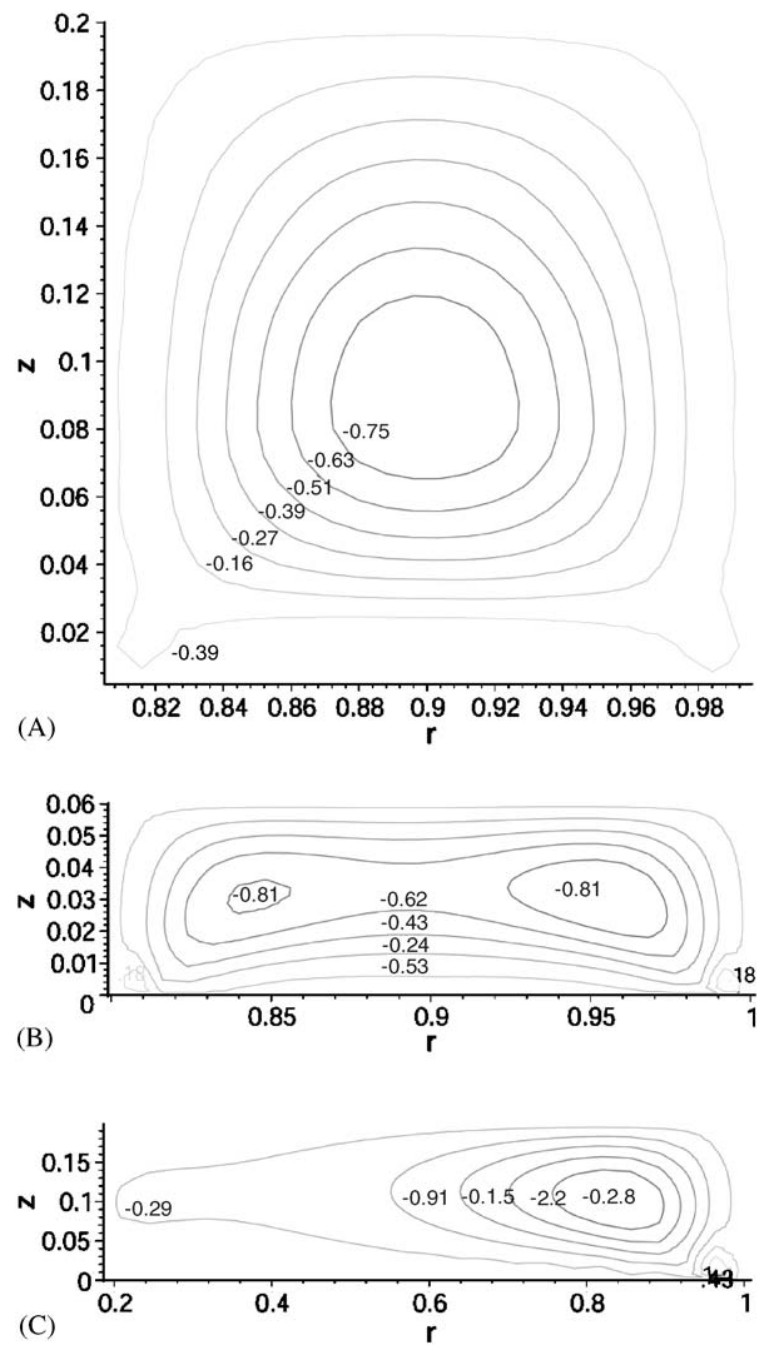

Fig. 5. Stream function $\psi$ isovalues for three different geometries at $O\left(R e^{2}\right)$ for $R e=1$ : (A) $10^{5} \psi$ with $r_{\mathrm{i}} / r_{\mathrm{o}}=0.8$ and $h / r_{\mathrm{o}}=0.2$. (B) $10^{6} \psi$ with $r_{\mathrm{i}} / r_{\mathrm{o}}=0.8$ and $h / r_{\mathrm{o}}=0.06$. (C) $10^{5} \psi$ with $r_{\mathrm{i}} / r_{\mathrm{o}}=0.1$ and $h / r_{\mathrm{o}}=0.2$. 
former published results even for large $R e$ values $(R e=73)$ (Fig. 4). This unexpected result not only confirms the analytical formulation for the azimuthal flow field but also allows the validity range in $R e$ of this model to be extended.

As regards the secondary flow field, no results are available in the literature in our $R e$ range. Here, different recirculating flows are made evident (Fig. 5) by means of the stream function isovalues and the channel geometry is found to play a key role (i.e. $r_{\mathrm{i}} / r_{\mathrm{o}}=0.8$ and $h / r_{\mathrm{o}}=0.06$, $r_{\mathrm{i}} / r_{\mathrm{o}}=0.1$ and $h / r_{\mathrm{o}}=0.2, r_{\mathrm{i}} / r_{\mathrm{o}}=0.8$ and $h / r_{\mathrm{o}}=$ 0.2 as a reference case). The reference geometry exhibits a main recirculation with a weak counterrotating cell near the rotating floor. As a matter of fact, reduction of the sub-phase depth or extension of the channel width can break the secondary flow symmetry or can give rise to two independent recirculations in the meridian plane. As crystallization experiments with this rotative well are still in progress, this information reveals to be of great interest in understanding the 2-D crystallization process at the interface.

\section{Conclusion}

A new device devoted to enhance the growth of 2-D single protein crystals has been proposed. The main advantage relates to the hydrodynamical flow the device produces in the underlying bulk. In this way, the technique is generic and could be applied to any protein able to crystallize in 2-D. This flow has been fully analytically modelled and appears to be greatly dependent on the channel geometry. Later this will consequently have to be well adapted to further crystallization studies. Experiments with this new device are in progress and should be compared in the near future with producing 2-D crystals with classical (static) techniques.

\section{Acknowledgements}

This work is supported by French Research and Education Ministre under ACI Contract PC10-01. The authors gratefully acknowledge enlightening discussions with Dr. Frank Fieschi and Pr. Eva Pebay-Peroula.

\section{References}

[1] E.E. Uzgiris, R.D. Kornberg, Nature 301 (1983) 125.

[2] E.E. Uzgiris, Biochem. Biophys. Res. Comm. 134 (1986) 819.

[3] R.D. Kornberg, S.A. Darst, Curr. Opin. Struct. Biol. 1 (1991) 642 .

[4] D.R. Shnek, D.W. Pack, D.Y. Sasaki, F.H. Arnold, Langmuir 10 (1994) 2382.

[5] W. Frey, J. Brink, W.S. Jr, W. Chiu, V. Vogel, Biophys. J. 93 (10) (1996) 4937.

[6] S. Courty, L. Lebeau, L. Martel, P.F. Lenne, F. Balavoine, W. Dischert, O. Konovalov, C. Mioskowski, J.F. Legrand, C. Venien-Bryan, Langmuir 18 (24) (2002) 9502.

[7] R.D. Kornberg, H.O. Ribi, Formation of Two-Dimensional Crystals of Proteins on Lipid Layers, vol. 2, Alan R. Liss, Inc., New York, 1987.

[8] A. Brisson, W. Bergsma-Schutter, F. Oling, O. Lambert, I. Reviakine, J. Crystal Growth 196 (1999) 456.

[9] A.J. Avila-Sakar, W. Chiu, Biophys. J. 70 (1996) 57.

[10] S. Koppenol, L.A. Klumb, V. Vogel, P.S. Stayton, Langmuir 15 (1999) 7125.

[11] T.C. Edwards, N. Malmstadt, S. Koppenol, M. Hara, V. Vogel, P.S. Stayton, Langmuir 18 (20) (2002) 7447.

[12] S.-W. Wang, C.R. Robertson, A.P. Gast, Langmuir 15 (1999) 1541.

[13] A.P. Gast, C.R. Robertson, S.-W. Wang, M.T. Yatcilla, Biomol. Eng. 16 (1999) 21.

[14] S.W. Wang, C. Robertson, A. Gast, S. Koppenol, T. Edwards, V. Vogel, P. Stayton, Langmuir 16 (11) (2000) 5199.

[15] P. Ratanabanangkoon, A.P. Gast, Langmuir 19 (5) (2003) 1794.

[16] R. Blankenburg, P. Meller, H. Ringsdorf, C. Salesse, Biochemistry 28 (1989) 8214.

[17] W.R. Schief, T. Edwards, W. Frey, S. Koppenol, P.S. Stayton, V. Vogel, Biomol. Eng. 16 (1999) 29.

[18] S.A. Darst, M. Ahlers, P.H. Meller, E.W. Kubalek, R. Blankenburg, H.O. Ribi, H. Ringsdorf, R.D. Kornberg, Biophys. J. 59 (1991) 387.

[19] M. Ahlers, R. Blankenburg, D.W. Grainger, P. Meller, H. Ringsdorf, C. Salesse, Thin Solid Films 180 (1989) 93.

[20] A.J. Pintar, The measurement of surface viscosity, Ph.D. Thesis, Illinois Institute of Technology, 1968.

[21] R.J. Manheimer, R.S. Schechter, J. Colloid Interface Sci. 32 (1970) 195.

[22] J.M. Lopez, A. Hirsa, J. Colloid Interface Sci. 206 (1) (1998) 231.

[23] A. Nayfeh, Perturbation Methods, first ed., Pure and Applied Mathematics, Wiley, New York, 1973.

[24] L. Quartapelle, F. Valz-Gris, Int. J. Numer. Meth. Fluids 1 (1981) 129.

[25] A.J. Pintar, A.B. Israel, D.T. Wasan, J. Colloid Interface Sci. 37 (1971) 52. 